\title{
Economic lifetime of a drilling machine: a case study on mining industry
}

\author{
Hussan Al-Chalabi* \\ Division of Operation, Maintenance and Acoustics, \\ Luleå University of Technology, \\ SE-971 87 Lulea, Sweden \\ and \\ Mechanical engineering Department, \\ College of Engineering, \\ University of Mosul, \\ 41002 Mosul, Iraq \\ Email: hussan.hamodi@1tu.se \\ *Corresponding author

\section{Jan Lundberg}

Division of Operation, Maintenance and Acoustics, Luleå University of Technology,

SE-971 87 Lulea, Sweden

Email: Jan.Lundberg@1tu.se

\section{Adam Jonsson \\ Division of Mathematic Science, Luleå University of Technology, SE-971 87 Lulea, Sweden \\ Email: adam.jonsson@1tu.se}

\begin{abstract}
Underground mines use many different types of machinery during the drift mining processes of drilling, charging, blasting, loading, scaling and bolting. Drilling machines play a critical role in the mineral extraction process and thus are important economically. However, as the machines age, their efficiency and effectiveness decrease, negatively affecting productivity and profitability and increasing total cost. Hence, the economic replacement lifetime of the machine is a key performance indicator. This paper introduces an optimisation model that gives the optimal lifetime for a drilling machine. A case study has been done at an underground Swedish mine to identify the economic replacement time of a drilling machine. It considers the purchase price, maintenance and operation costs, and the machine's second-hand value. Findings show that the economic replacement lifetime of a drilling machine in this mine is 96 months. The proposed model can be used for other underground mining machines.
\end{abstract}

Keywords: drilling machine; economic replacement time; optimisation model; asset management. 
Reference to this paper should be made as follows: Al-Chalabi, H., Lundberg, J. and Jonsson, A. (2015) 'Economic lifetime of a drilling machine: a case study on mining industry', Int. J. Strategic Engineering Asset Management, Vol. 2, No. 2, pp.177-189.

Biographical notes: Hussan Al-Chalabi received his BEng in Mechanical Engineering from Mosul University, Iraq in 1994 and MSc in Mechanical Engineering in Thermal Power from Mosul University, Iraq in 2008. Then he joined the Department of Mechanical Engineering at Mosul University as a lecturer. Since 2011, he joined the Division of Operation, Maintenance and Acoustics at LTU as a doctoral student.

Jan Lundberg is a Professor of Machine Elements at Luleå University of Technology and also a Professor in Operation and Maintenance with focus on product development. During the years 1983-2000, his research concerned mainly about engineering design in the field of machine elements in industrial environments. During the years 2000-2006, his research concerned mainly about industrial design, ergonomic and related problems as cultural aspects of design and modern tools for effective industrial design in industrial environments. From 2006 and forward, his research is completely focused on maintenance issues like methods for measuring failure sources, how to do design out maintenance and how to design for easy maintenance.

Adam Jonsson is a Senior Lecturer in the Department of Engineering Sciences and Mathematics, Luleå University of Technology, Sweden. He received his $\mathrm{PhD}$ in Statistics in 2008. His research is in applied probability and social welfare economics.

This paper is a revised and expanded version of a paper entitled 'Economic lifetime of a drilling machine: a case study on mining industry' presented at the MPMM 2013, Lappeenranta, Finland, 12-13 September 2013.

\section{Introduction}

Mines are a source of energy resources and minerals. Thus mines play a key role in the economic growth of industrialised countries. Many different machines are essential in the mineral extracting process; one example is the drilling machine. Economic competition and customer demand have pushed companies to achieve higher production rates through greater mechanisation and automation. This has led to high investments in equipment (Duffuaa et al., 1998). The trend towards larger and more expensive equipment in underground mining to achieve cost effectiveness raises the question of replacement. When should a company replace the existing equipment to minimise cost? Because drilling machines are a key element of production, they are important economically. A significant cost issue is the machine's maintenance cost. At long-term profitability, the maintenance can play a key role for a firm, where it can have major impact on cost (Baglee and Knowles, 2010). Up to $40 \%$ of the total production cost of the heavy industries represents by maintenance cost (Lee and Wang, 1999). A study by the Swedish mining industry shows that the cost of maintenance in a highly mechanised mine can be $40-60 \%$ of the operating cost (Danielson, 1987). Thus, the important factors behind these 
costs needs to be measured for their performance, like; measuring value created by the maintenance, justifying investment and revising resource allocations (Parida and Kumar, 2006). These factors are related to the cost of mining equipment and its economic lifetime.

\section{Literature survey}

The economic replacement of productive machines is a fundamental question faced by researchers, economic engineers and management engineers. Researchers concerned with cost optimisation are especially interested in the optimum replacement time of production equipment.

The growing interest in modelling the economic lifetime of capital equipment has dramatically increased during recent decades, since the first optimal asset replacement models were developed by Bellman in 1955 (Hritonenko and Yatsenko, 2008). Elton and Gruber (1976) proved that an equal life policy was optimal on the infinite horizon under technological change. Correspondingly, many later replacement models assumed that the optimal lifetime of assets was constant. Many researchers have studied optimal procedures for replacing old equipment with new. Some have used the theory of dynamic programing considering technological changes under infinite and finite horizon (Bellman, 1955; Bethuyne, 1998; Elton and Gruber, 1976; Hartman, 2005; Hritonenko and Yatsenko, 2008; Mardin and Arai, 2012). Another study optimised the lifetime of capital equipment using integral models (Yatsenko and Hritonenko, 2005); the study designed a general investigation framework for optimal control of the integral models. Scarf and Bouamra (1999) address the capital replacement problem using a discounted cost criterion over a finite time horizon. They present a robust approach to solving the fleet replacement problem in which the fleet size is allowed to vary at replacement. Hritonenko and Yatsenko (2007) study optimal equipment replacement without paradoxes. Using an integral model to calculate the economic lifetime of equipment and considering technological changes (TC), they show that the economic lifetime of equipment is shorter when the embodied TC is more intense.

Many researchers have studied the optimal lifetime of capital equipment through economic theory by using vintage capital models, represented mathematically by nonlinear Volterra integral equations with unknown limits of integration (Boucekkine et al., 1997; Cooley et al., 1997; Hritonenko and Yatsenko, 2003; Hritonenko, 2005). Hartman and Murphy (2006) presented a dynamic programming approach to the finite-horizon equipment replacement problem with stationary cost. Their model was introduced to study the relationship between the infinite-horizon solution (continuously replace equipment at the end of its economic lifetime) and the finite-horizon solution. Kärri (2007) studied the optimal replacement time (ORT) of old machine. He used an optimisation model which minimises the machine cost; the model has been built for capacity expansion and replacement situation. The costs of old machine were modelled with simple linear functions and all costs that he used in his study are real costs without inflation. He also used another optimisation model which maximises profit. Hritonenko and Yatsenko (2009) constructed a computational algorithm to solve a nonlinear integral 
equation. The solution is important for finding the optimal policy of equipment replacement under technological advances. Other researchers such as (Galar et al., 2012) used different cost models to define the efficiency of the operation of an industrial installation in a finite time horizon. They develop a methodology for the calculation of operation costs in industrial facilities.

The optimum replacement age of equipment is defined as that time at which the total cost is at its minimum value (Jardine and Tsang, 2006). In this paper the economic lifetime of drilling machine is defined as the optimal age which minimises the total adjusted cost value. The term 'total adjusted cost value' is defined as the summation of the machine purchase price, operating cost, maintenance cost and machine second-hand value. The machine second-hand value is the value of the machine in case the company wants to sell the machine at any time during the machine's planned lifetime. In this study, the most influential factors in the drilling machine's economic lifetime have been considered; cost data were collected for four years.

As the literature review shows, there are many researchers have focused on estimating the optimal lifetime of equipment considering technological changes by using integral models, theories of dynamic programming, vintage capital models and algorithms to solve a nonlinear integral equations. Despite the available information, it can be difficult for users to implement complex models to calculate the ORT of equipment. Moreover, these models sometimes require specific types of data that, as in our case study, are not available. These can include data on production output, technological labour/output coefficient, revenue, profit etc. Thus, the aim of this study is to present a practical optimisation model to more easily estimate the economic lifetime of drilling machine, using available data from the mining company. The objective of our optimisation model is to minimise the total adjusted cost value of the drilling machine.

The rest of the study is as follows. Section 3 describes the drilling machine, while Section 4 discusses data collection. Methodology and model development are presented in Section 5; results and a discussion appear in Section 6; Section 7 offers concluding remarks and Section 8 offers future work.

\section{The drilling machine}

All drilling machines for mining applications are composed of similar operational design units: cabin, boom, rock drill, feeder, service platform, front jacks, hydraulic pump, rear jack, electric cabinet, hose reeling unit, cable reeling unit, diesel engine, hydraulic oil reservoir, operator panel and water tank. A typical drilling machine is shown in Figure1 (Atlas Copco Rock Drills AB, 2010).

Drilling machines manufactured by different companies have different technical characteristics, e.g., capacity and power. Based on the operation manuals, field observations and maintenance reports from the collaborating mine, in this study the drilling machine is considered a system divided into several major subsystems connected in a series configuration. If any subsystem fails, the operator will stop the machine to maintain it. Thus, all machine subsystems work simultaneously to achieve the desired function. Figure 2 is a block diagram of drilling machine subsystems. 
Figure 1 Drilling machine

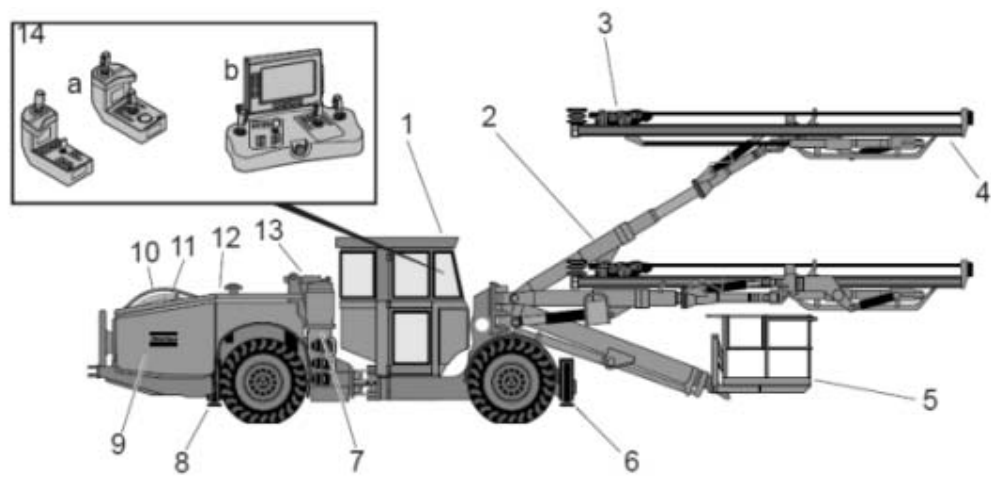

$\begin{array}{ll}1 & \text { Cabin } \\ 2 & \text { Boom } \\ 3 & \text { Rock drill } \\ 4 & \text { Feeder } \\ 5 & \text { Service platform } \\ 6 & \text { Front jacks } \\ 7 & \text { Hydraulic pump }\end{array}$

$$
\begin{array}{ll}
8 & \text { Rear Jack } \\
9 & \text { Electric cabinet } \\
10 & \text { Hose reeling unit } \\
11 & \text { Cable reeling unit } \\
12 & \text { Diesel engine } \\
13 & \text { Hydraulic oil reservoir } \\
14 \mathrm{a} & \text { Operator panel, designed for seated operator } \\
14 \mathrm{~b} & \text { Operator panel, designed for standing operator }
\end{array}
$$

Source: Atlas Copco Rock Drills AB

Figure 2 Block diagram of drilling machine subsystems

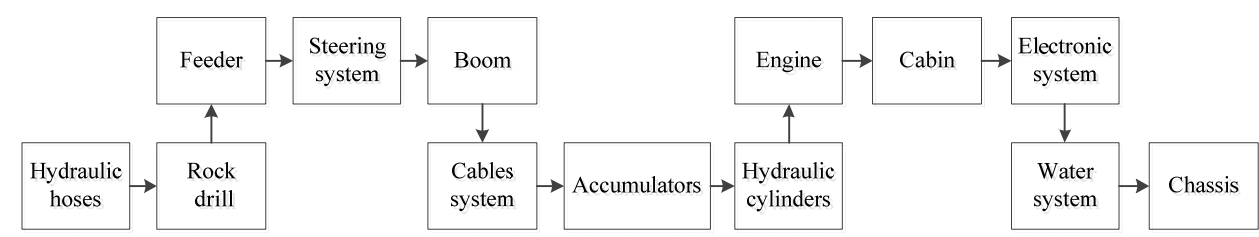

\section{Data collection}

The cost data used in this study were collected over four years in the Maximo computerised maintenance management system (CMMS). The cost data contain corrective and preventive maintenance costs and time to repair. The corrective and preventive maintenance cost contains spare part and labour (repair man) cost. In CMMS, the cost data are recorded based on calendar time. Since drilling is not a continuous process, the operation cost is estimated by considering the utilisation of the machine. All costs data that used in this study are real costs without inflation.

\section{Methodology and model development}

In this study, the notation for maintenance and operating costs as well as the machine purchase price with other quantities used in the optimisation problem is given in Table 1 . 
Table 1 Definition of model variables

\begin{tabular}{lc}
\hline Variable & Definition \\
\hline$c u$ & Currency unit \\
$p p$ & Purchase price $(\mathrm{cu})$ \\
$r T$ & Replacement time (month) \\
$M C$ & Maintenance cost (cu) \\
$C M C$ & Corrective maintenance cost (cu) \\
$P M C$ & Preventive maintenance cost (cu) \\
$S P C$ & Spare part cost $(\mathrm{cu})$ \\
$L C$ & Labour cost $(\mathrm{cu})$ \\
$O C$ & Operating cost $(\mathrm{cu})$ \\
$S H V(t)$ & Second-hand value $(\mathrm{cu})$ \\
$D r$ & Depreciation rate \\
$B V_{l}$ & Booking value at first day of operation (cu) \\
$S V$ & Scrap value (cu) \\
$T A C_{i}$ & Total adjusted cost (cu) \\
\hline
\end{tabular}

The maintenance costs (corrective and preventive) for each operating month were calculated as follows:

$$
\begin{aligned}
& M C=C M C+P M C \\
& C M C=S P C+L C \\
& P M C=S P C+L C
\end{aligned}
$$

Determination of the utilisation of the drilling machine was based on the estimation of the operating cost because drilling is not a continuous process in the collaborating mine.

The company planned to use the machine for ten years. For that reason, extrapolation has been done for maintenance and operation cost data. Figures 3 and 4 illustrate the expected maintenance and operating costs data extrapolation.

Figure 3 Expected maintenance cost

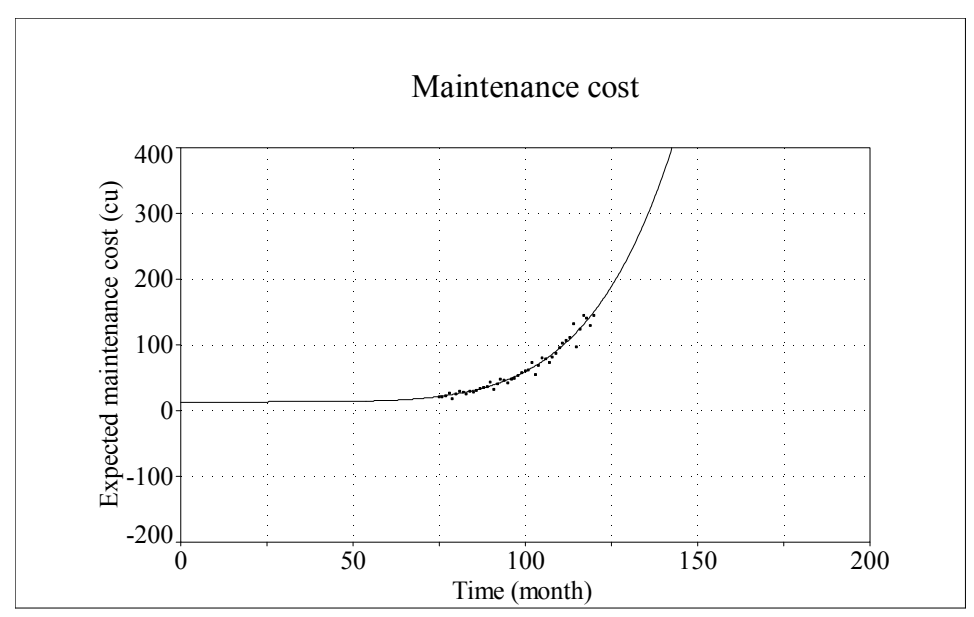


Figure 4 Expected operating cost

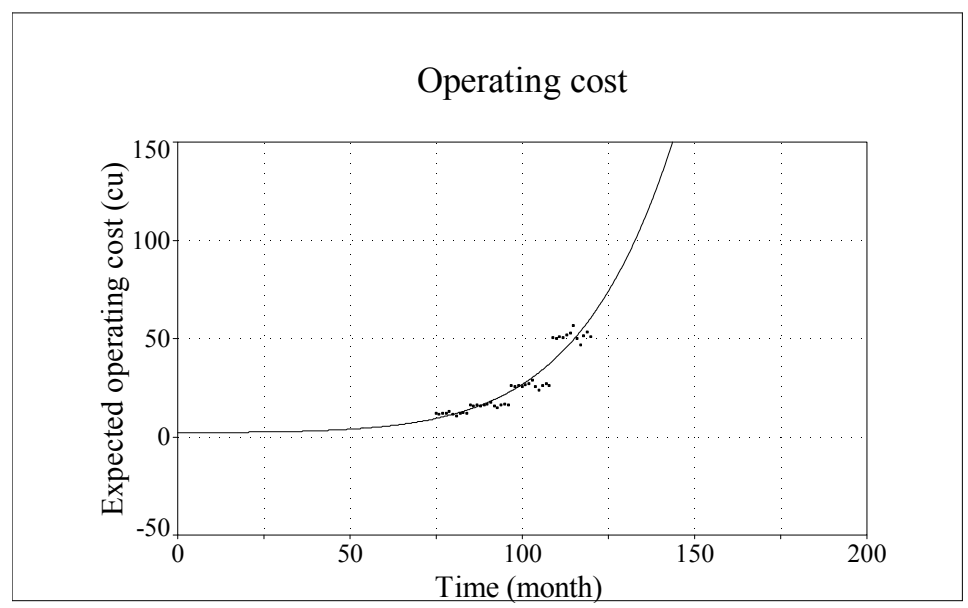

In Figures 3 and 4, dots represent the real data for maintenance and operating costs. Curve fitting is done by using Table curve 2D software to show the behaviour of the machine in term of these costs before and after the time of collected data. Note that the fitting would be better if more data were available for a time period of more than four years. This software uses the least squares method to find a robust (maximum likelihood) optimisation for nonlinear fitting. The figures show that the maintenance and operating costs increase over time. Possibly, the number of failures increases with time and/or the machine consumes more energy due to machine degradation. It is worth mentioning that the drilling machine in this case study has no multi-level preventive maintenance program. In addition, it was new at the start of utilisation. This is the main reason why the maintenance cost is quite low in earlier months. The history shows that when the maintenance costs started growing, the user company began to keep track of cost data.

A declining balance depreciation model was used to model the second-hand value of the machine after each month of operation. The second-hand value of the machine was estimated from the following formula (Luderer et al., 2010; Eschenbach, 2010):

$$
S H V(t)=B V_{1} \times(1-D r)^{t}
$$

where $(t)$ represents time (month), $t=1,2,3 \ldots 120$.

The depreciation rate that allows for full depreciation by the end of the planned lifetime of the machine was modelled by the following formula (Luderer et al., 2010):

$$
D r=1-\left(\frac{S V}{B V_{1}}\right)^{\frac{1}{L}}
$$

where $(L)$ represents the planned lifetime of the machine (in this case 120 months). The machine's second-hand value was modelled by the following formula:

$$
S H V(t)=(p p-a) \times(1-D r)^{t}
$$


where $a$ represents the machine's depreciation in value on the first day of use. It is assumed that the machine's total lost value will be $10 \%$ on the first day of use. Hence, the machine's second-hand value at the end of the first day of operation is $(p p-a)=0.9 \times p p$.

We have chosen the declining balance depreciation model because it is suitable for representing the depreciation of this case. The declining balance depreciation model assumes that more depreciation occurs at the beginning of the equipment's planned lifetime, less at the end. The equipment is more productive when it is new and its productivity declines continuously due to equipment degradation. Therefore, in the early years of its planned lifetime, it will generate more revenue than in later years. In accountancy, depreciation refers to two aspects of the same concept. The first is the decrease in the equipment's value. The second is the allocation of the cost of the equipment to periods in which it is used. The scrap value is an estimate of the value of the equipment at the time it is sold or disposed of; in this study, the scrap value was assumed as $50 \mathrm{cu}$. Due to the confidentiality policy of the company, all cost data were encoded and expressed as currency unit cu. Figure 5 shows the drilling machine's second-hand value using the declining balance depreciation model.

Figure 5 Expected machine second-hand value

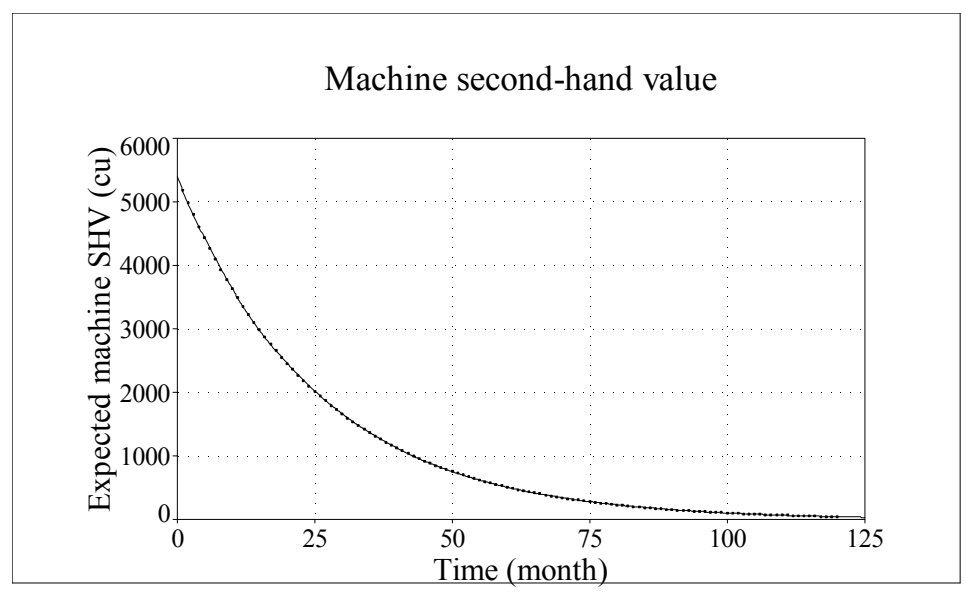

Figure 5 shows that the machine's second-hand value decreased with time until it reached scrap value at the end of its planned lifetime.

The next step in the calculations is to compute the total adjusted cost $T A C_{i}$ during a period $i$ of operation using the following formula:

$$
T A C_{i}=p p+\left[\sum_{k=1}^{r T}\left(M C_{i}+O C_{i}\right)\right]-S H V(r T)
$$

where $i=1,2,3, \ldots, n$. $n$ represents the number of operation months.

For example, $T A C_{1}$ represents the total adjusted cost after the first month of operation and $T A C_{2}$ represents the total adjusted cost after two months of operation. The optimisation model assumes that the replacement machines have the same performance and cost as the old machines. The number of replacements during the optimisation time horizon is determined by the following formula: 


$$
N=\frac{\text { Optimisation time horizon }}{\text { Machine replacement time }}=\frac{T}{r T}
$$

Figure 6 illustrates the expected total adjusted cost of the machine over the machine's planned lifetime.

Figure 6 Expected total adjusted cost

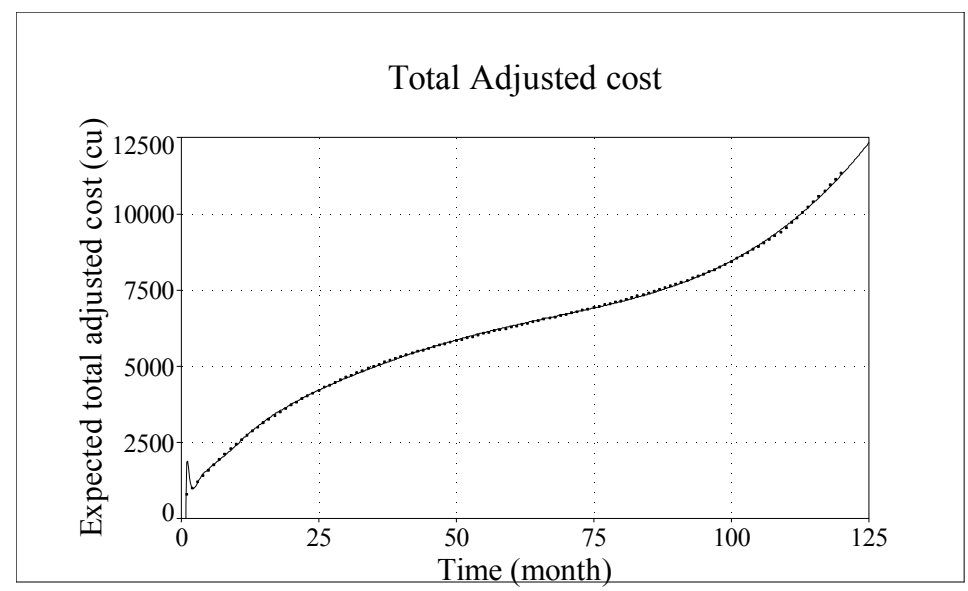

Figure 6 shows that the total adjusted cost increased with time for two reasons: first, maintenance and operation costs increased over time; second, the machine's second-hand value decreased over time.

To show the behaviour of the optimisation curve after the optimal replacement time, we assumed that the machine would survive for a finite time horizon of 360 months; see Figure 7. The total adjusted cost for each operating months of the optimisation time horizon was computed by using the total adjusted cost function. This function is the fit of the calculated total adjusted cost over the machine's planned lifetime (120 months). Table curve 2D software was used to find the total adjusted cost function which can be used for any time horizon. Equation (9) expresses the total adjusted cost function used here:

$$
\begin{aligned}
T A C(t)= & a+b \times \ln (t)+c \times[\ln (t)]^{2}+d \times[\ln (t)]^{3}+e \times[\ln (t)]^{4}+f \times[\ln (t)]^{5} \\
& +g \times[\ln (t)]^{6}+h \times[\ln (t)]^{7}+i \times[\ln (t)]^{8}+j \times[\ln (t)]^{9}
\end{aligned}
$$

where $a=814.0, b=13834.3, c=-56718.9, d=95747.0, e=-86169.8, f=45829.6$, $g=-14863.2, h=2890.3, i=-309.9$, and $j=14.1$.

The optimal replacement time $(r T)$ which minimises the total adjusted cost value can be calculated by the following formula:

$$
\operatorname{Min}\left(T A C_{\text {value } r T}\right)=\operatorname{Min}\left[\left\{p p+\left[\sum_{k=1}^{r T}\left(M C_{i}+O C_{i}\right)\right]-S H V(r T)\right\} \times N\right]
$$




\section{Result and discussion}

Microsoft Excel ${ }^{\mathrm{TM}}$ software was used to enable variation of the $r T$ of equation (10) for a period of 360 months, to identify the optimum replacement lifetime of a drilling machine that minimises $T A C_{\text {value } r T}$. Figure 7 shows $T A C_{\text {value } r T}$ versus different replacement time $r T$. As is evident, the lowest possible $T A C_{\text {value }} r T$ can be achieved by replacing the machine every 96 months ( 8 years). However, it must be noted that $r T=96$ months generates the absolute minimum cost. As Figure 7 also shows, within that, there is a range (e.g., 90-102 months) when the minimum $T A C$ value can still be achieved in practice. In this study, we call it economic replacement range. Finding the economic replacement range is an important result of our study as it can help users in their planning. A decision to replace the machine before or after this economic replacement range incurs greater cost for the user company.

Figure 7 Machine economic replacement time

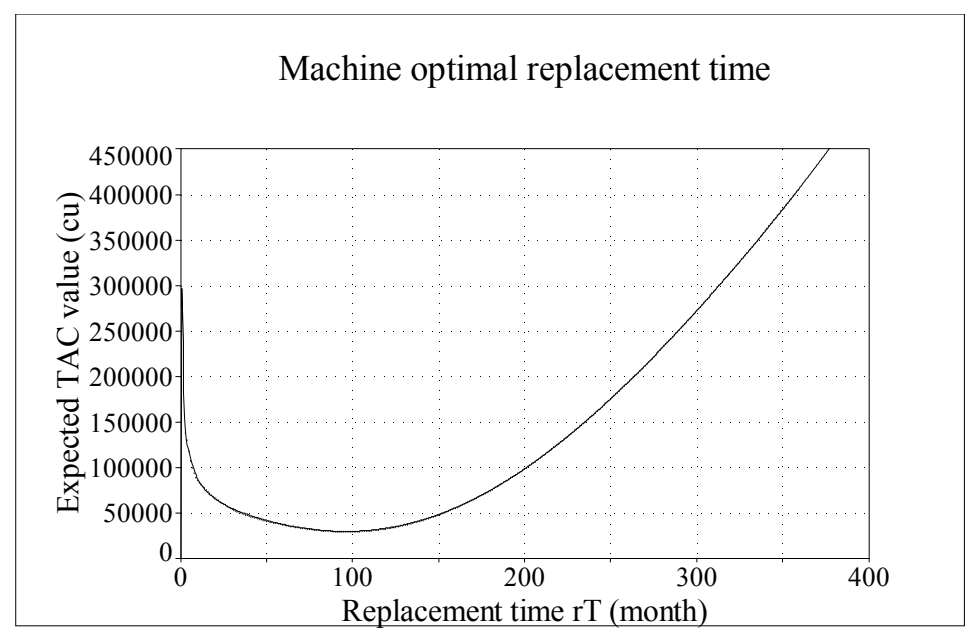

The use of a lower economic replacement age (i.e., less than 90 months) incurs higher costs due to the high investment cost. Meanwhile, if the lifetime of the machine exceeds the upper limit of this range (i.e., more than 102 months), losses will increase for two reasons:

1 the maintenance and operating costs increase when the operating time increases due to machine degradation

2 the machine's second-hand value will decrease until it reaches scrap value at the end of its planned lifetime which is 120 months.

\section{Concluding remarks}

This study presents a comprehensive and practical approach which can provide the economic replacement time of an underground mining machine. Therefore, we derive the following conclusions from the present study: 
1 This study gives a basic approach to determining the economic lifetime of a drilling machine, which facilitates the management in making investment decision making. Therefore, a decision to replace the old machine before or after its economic life time will incurs greater cost.

2 When using the purchase price, operating and maintenance costs, and second-hand value, the economic lifetime of equipment is the minimum sum of the associated total adjusted cost value.

3 According to the results obtained from the optimisation curve, the absolute economic lifetime of the drilling machine at the case study's mine is 96 months (eight years) of operation. However, the economic lifetime has a range of 90 to 102 months, during which the total adjusted cost value remains almost constant. This means that the company has the flexibility to make replacements within the optimum replacement age range, i.e., 12 months. Therefore, there is no fixed date or age at which the $T A C$ value is minimum. In general, a range of months provides the minimum $T A C$ value.

4 This model helps engineers and decision-makers decide when it is best economically to replace an old machine with a new one. Thus, it can be extended to more general applications in mining industry.

\section{Future works}

Further research is needed to extend the developed model by performing a sensitivity analysis to identify the effect of purchase price, operating and maintenance costs on the economic replacement time of the drilling machine on mining industry. It should be noticed that in this paper we have presented a simple and basic model for economical replacement time of mining machinery. Therefore, in future work and research more important economic factors such as net present value of money, discount rate will be added to achieve a general comprehensive model for replacement time of mining equipment. The reliability and maintainability aspects may be considered as well.

\section{Acknowledgments}

The authors are grateful to referees and the guest editors for useful remarks. The authors would like to thank Atlas Copco for their financial support. The people at Boliden AB who helped in this research are gratefully acknowledged as well. The authors would also like to thank Alireza Ahmadi and Behzad Ghodrati for their help. 


\section{References}

Atlas Copco Rock Drills AB (2010) Atlas Copco Boomer L1C, L2C Mk 7 B Operator's Instructions, Manual Edition, Atlas Copco Rock Drills AB, Sweden.

Baglee, D. and Knowles, M. (2010) 'Maintenance strategy development within SMEs: the development of an integrated approach', Control and Cybernetics, Vol. 39, No. 1, pp.275-303.

Bellman, R. (1955) 'Equipment replacement policy', Journal of Society for Industrial and Applied Mathematics, Vol. 3, No. 3, pp.133-136.

Bethuyne, G. (1998) 'Optimal replacement under variable intensity of utilization and technological progress', The Engineering Economist: A Journal Devoted to the Problems of Capital Investment, Vol. 43, No. 2, pp.85-105.

Boucekkine, R., Germain, M. and Licandro, O. (1997) 'Replacement echoes in the vintage capital growth model', Journal of Economic Theory, Vol. 74, No. 2, pp.333-348.

Cooley, T.F., Greenwood, J. and Yorukoglu, M. (1997) 'The replacement problem', Journal of Monetary Economics, Vol. 40, No. 3, pp.457-499.

Danielson, B. (1987) A Study of Maintenance Problems in Swedish Mines, Study Report, Idhammar Konsult AB, in Swedish.

Duffuaa, S.O., Raouf, A. and Campbell, J.D. (1998) Planning and Control of Maintenance Systems: Modeling and Analysis, 1st ed., Wiley Publisher.

Elton, E.J. and Gruber, M.J. (1976) 'On the optimality of an equal life policy for equipment subject to technological improvement', Operational Research Quarterly, Vol. 27, No. 1, pp.93-99.

Eschenbach, T. (2010) Engineering Economy: Applying Theory to Practice, 3rd ed., Oxford University Press New York.

Galar, D., Kumar, U., Sandborn, P. and Morant, A. (2012) 'O\&M efficiency model: a dependability approach', 25th International Congress on Condition Monitoring and Diagnostic Engineering, IOP Publishing, Journal of Physics: Conference Series, Conference 1, Vol. 364.

Hartman, J.C. (2005) 'A note on a strategy for optimal equipment replacement', Production planning \& control, Vol. 16, No. 7, pp.733-739.

Hartman, J.C. and Murphy, A. (2006) 'Finite-horizon equipment replacement analysis', IIE Transactions, Vol. 38, No. 5, pp.409-419.

Hritonenko, N. (2005) 'Optimization analysis of a nonlinear integral model with applications to economics', Nonlinear Studies, Vol. 12, No. 1, pp.59-71.

Hritonenko, N. and Yatsenko, Y. (2003) Applied Mathematical Modeling Of Engineering Problems, Kluwer Academic Publishers.

Hritonenko, N. and Yatsenko, Y. (2007) 'Optimal equipment replacement without paradoxes: a continuous analysis', Journal of the Operations research letters, Vol. 35, No. 2, pp.245-250.

Hritonenko, N. and Yatsenko, Y. (2008) 'The dynamics of asset lifetime under technological change', Journal of the Operations Research Letters, Vol. 36, No. 5, pp.565-568.

Hritonenko, N. and Yatsenko, Y. (2009) 'Integral equation of optimal replacement: analysis and algorithms', Journal of Applied Mathematical Modelling, Vol. 33, No. 6, pp.2737-2747.

Jardine, A. and Tsang, A. (2006) Maintenance, Replacement, and Reliability Theory and Application, Taylor \& Francis Group.

Kärri, T. (2007) Timing of Capacity Change: Models for Capital Intensive Industry, PhD thesis, Lappeenrannan Teknillinen Yliopisto, Lappeenranta University of Technology, Finland.

Lee, J. and Wang, B. (1999) Computer-Aided Maintenance: Methodologies and Practices, Vol. 5, Kluwer Academic Publisher.

Luderer, B., Nollau, V. and Vetters, K. (2010) Mathematical Formulas for Economists, Springer-Verlag Berlin Heidelberg. 
Mardin, F. and Arai, T. (2012) 'Capital equipment replacement under technological change', The Engineering Economist, Vol. 57, No. 2, pp.119-129.

Parida, A. and Kumar, U. (2006) 'Maintenance performance measurement (MPM): issues and challenges', Journal of Quality in Maintenance Engineering, Vol. 12, No. 3, pp.239-251.

Scarf, P.A. and Bouamra, O. (1999) 'Capital equipment replacement model for a fleet with variable size', Journal of Quality in Maintenance Engineering, Vol. 5, No. 1, pp.40-49.

Yatsenko, Y. and Hritonenko, N. (2005) 'Optimization of the lifetime of capital equipment using integral models', Journal of industrial and management optimization, Vol. 1, No. 4, pp.415-432. 